\title{
LINGUAGENS INVESTIGAÇÃO-AÇÃO EM EDUCAÇÃO MUSICAL
}

\author{
Oscar Daniel Morales Mello
}

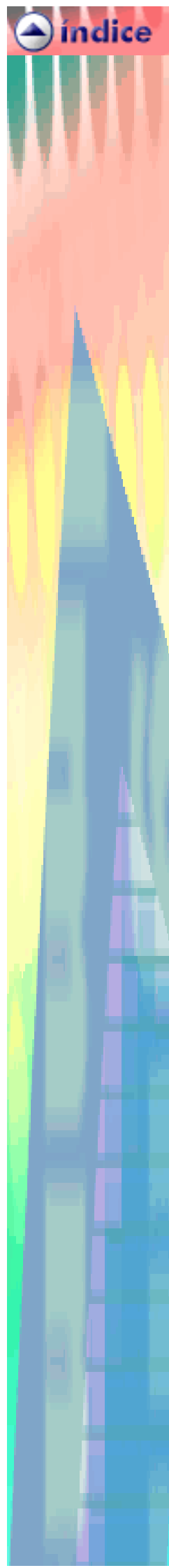

Este grupo está trabalhando desde 1997. É integrado por acadêmicos e professores dos cursos de Licenciatura e Bacharelado em Música do Centro de Artes e Letras da Universidade Federal de Santa Maria, contando ainda com a colaboração de pesquisadores, professores, acadêmicos de outros cursos da UFSM, assim como de professores do $I^{\circ}$ e $I^{\circ}$ Grau, das comunidades com as quais o nosso grupo tem interagido, como Santa Maria, São Sepé e Santo Cristo.

A forma investigativa sobre a qual este grupo trabalha parte da problematização da educação musical em sala de aula, através da participação de educandos e educadores num processo dialógico colaborativo no qual os envolvidos são sujeitos ativos-críticos ${ }_{\mathbf{L}}$ todos eles investigando a sua realidade.

O processo reflexivo do grupo sobre estas dificuldades aponta para a necessidade de definir mudanças no espaço escolar, tanto formal quanto informal, através de uma releitura da realidade concreta onde essas dificuldades vem ocorrendo, utilizando como instrumento o que-fazer dos sujeitos integrantes do processo.

Esta proposta de investigação ambiciona a interação dialógica como o caminho para uma melhor compreensão do que-fazer cotidiano na sala de aula, capaz de propiciar, aos agentes educativos da mesma, a possibilidade de partir da reflexão das práticas individuais para a análise coletiva das ações educativas, propondo modificações a serem investigadas.

Estas ações fazem parte de um programa de investigação-ação, como processo educativo que está a nos proporcionar um melhor conhecimento do nosso fazer. Com isto procura-se aprender em grupo, com as ações participantes dos sujeitos envolvidos, trabalhando com as relações homem-meio num processo cultural, sistematizando as auto-reflexões individuais e reflexões coletivas dos sujeitos como investigadores ativos-críticos sobre a própria prática educativa.

À medida em que nosso trabalho foi avançando, começaram a ficar claras algumas alternativas a serem seguidas no processo de modificação da realidade encontrada. É por isto que o grupo de Investigação-ação em Educação Musical parte de uma divisão que tenta ordenar as idéias surgidas no recorte desta realidade investigada. Partimos do princípio de que a educação tem uma relação muito estreita com a arte e, ao entrar na sala de aula, o 


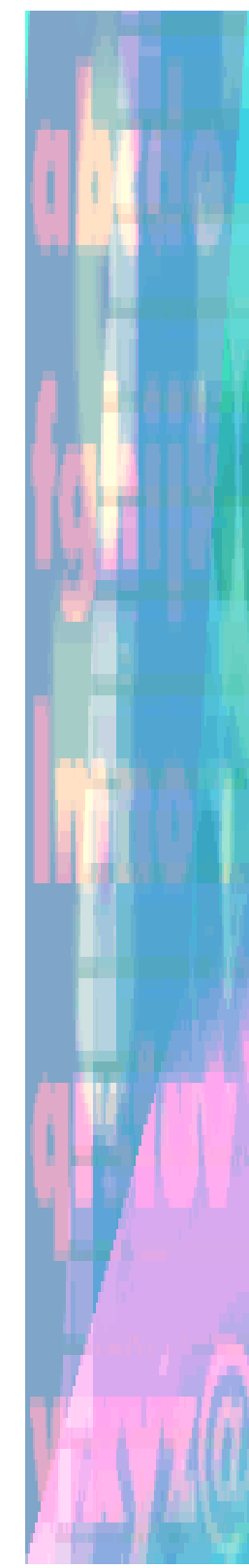

professor começa uma relação de criação de conhecimentos com os alunos, que encerra a própria criação artística.

Para que esta problematização tenha uma realização mais efetiva, o grupo trabalha em vários projetos fazendo com que as ações realizadas tenham um caráter mais abrangente. Estas são realizadas com professores e alunos em realidades diferentes, meio urbano e rural, o que nos tem proporcionado experiências qualitativamente importantes. Trabalhamos em realidades diversas, como: Lar Metodista, em Santa Maria, no Município de Santo Cristo, durante o ano de 1997; e Município de São Sepé, nos anos de 1996, 1997 e 1998.

Neste último, estivemos no dia 11 de novembro, trabalhando na localidade de Cerrito do Ouro, na Escola Núcleo Coronel Chananeco. Estruturamos as atividades, divididos em dois grupos: pela parte da manhã, com os alunos e professores das quintas e sextas séries; no período da tarde, com a pré-escola, primeira, segunda, terceira e quarta séries. No total, o grupo esteve formado por 196 alunos, 9 professores, 8 mães de alunos, direção da escola, 2 professores funcionários da Secretaria Municipal de Educação e Cultura, o Presidente da Fundação Cultural Afif Simões Filho, 8 acadêmicos do Curso de Licenciatura em Música e o Coordenador do Grupo de Investigação-ação em Educação Musical.

Seguindo o processo de reflexão-ação, fazemos uma avaliação permanente para balizar a nossa caminhada. Neste sentido é importante que possamos transcrever as considerações de alunos que conosco trabalharam no transcurso destas ações, na Escola Coronel Chananeco, Cerrito do Ouro, São Sepé.

\footnotetext{
". . . Eu achei muito legal, nós já somos todo o mundo amigo, e a gente gostou do professor, nos ensinou muito bem, o senhor também é muito legal, brinca com a gente, agora nos gostamos mais de música " (G. aluno da sexta série).

". . . E que nós, não é só escrever, botando a voz prá fora nós também aprendemos" (L. aluno da Quinta série)
}

As palavras destes alunos nos permitem dimensionar o quanto podemos avançar, através de uma educação dialógica, dentro de um processo crítico-reflexivo. Ao mesmo tempo, encontramos neles a motivação que impulsiona o processo de formação do professor, ao mesmo tempo em que, junto com o educando, transforma-se a realidade através de ações inseridas no processo. Esta linguagem artítico-musical, que é própria de todo ser humano, fica expressa, e a partir dela trabalha-se na construção estético-musical junto com o educando. 
No dizer de FREIRE(1987), o ato de conhecer possui uma amplitude que o leva a desvelar um objeto e esta tarefa encerra muitos momentos em que o educador é um artista disposto a caminhar, se movimentar, dialogar, enfim, integrar-se e atuar em sala de aula, desempenhando o papel de orientador numa relação social, estética e política com os alunos.

\footnotetext{
O que faz da educação uma arte é precisamente quando a educação é também um ato de conhecer. Para mim, conhecer é alguma coisa bonita. A amplitude do ato de conhecer é desvelar um objeto, o desvelar dá "vida" ao objeto. Esta é uma tarefa artística porque nosso conhecimento tem uma dada qualidade de vida, cria e anima objetos com o nosso estudo a respeito deles ... (FREIRE, Journal of Education, Boston University, Vol. 169, n 3, 1987, pp. 30-31)
}

A partir do momento em que o educador entra na sala de aula, inicia uma relação estética entre os sujeitos imersos no processo, e neste, o professor terá a desempenhar uma estratégia e um papel diretivo, através dos quais os momentos de teoria e de prática somam-se no ato de conhecer, criando e (re)criando objetos de interesse coletivo, socializando o conhecimento e formando educandos-educadores.

Através de diversas ações, nosso grupo tem caminhado na construção de alternativas pedagógicas que possam servir para esclarecer cada vez mais sobre estas características do processo de ensino-aprendizagem. A conscientização da natureza do mencionado processo faz com que possamos avançar na nossa formação profissional, conhecer o que nós de fato fazemos, equilibrar teoria e prática.

Por muitas vezes podemos pensar que o professor, depois de passar pelo seu curso de formação, está pronto e, a partir de então, deve avançar fazendo a luz na sua caminhada. Mas esta não será autêntica se deixarmos sem atendimento a totalidade do educando, como ser humano social e político por natureza.

O professor tem a oportunidade de trabalhar estes componentes que permitem estabelecer os vínculos com a própria identidade cultural dos educandos, utilizando para tanto novos caminhos e procurando novas alternativas para a educação musical. Para que isto aconteça, é importante que se procure a música que está no ser humano e não fora dele, aquela música que faz parte da sua formação sóciocultural.

Neste sentido, o grupo tem trabalhado a música como linguagem; o inato e o adquirido em música; a inter-relação educador e educando; os conhecimentos específicos da música; a educação musical dentro dos espaços escolares formais e/ou informais; e a troca com o ambiente social. 
Através das ações desenvolvidas, ao mesmo tempo em que nos deixaram conhecer os problemas e anelos da comunidade; também deixam aflorar as contradições do nosso sistema formativoeducacional, particularmente no que diz respeito ao ensino das artes e, entre elas, da música.

A prática da investigação-ação propicia transformar o espaço de aula num lugar onde educador-educando ou educando-educador partilham das ações e reflexões coletivas e se constróem alicerçados na dialogicidade, na participação, no envolvimento e comprometimento de sua existência humana da vivência escolar e social.

Este fazer reflexivo, dialógico e comprometido assume-se como caminho para uma prática educacional emancipatória.

\section{BIBLIOGRAFIA:}

ANGULO, J. F. "Investigación-acción y Curriculum: Una Nueva Perspectiva en la Escuela", Investigación en la Escuela, n. 11, p. 39- 49, Sevilla, 1990.

COSTA, M. C. V. A Caminho de uma pesquisa-ação crítica. In Educação e Realidade. Porto alegre: v.16, $n^{\circ}$ 2, jul/dez. 1991: p 47- 52.

CAMPOS, Denise Álvares. Oficina de Música: Uma caracterização de sua metodologia. Goiânia, Cegraf/ UFG, 1988.

CARR, W. e KEMMIS, S. Teoria crítica de la enseñanza: Investigación-acción en la formación del professorado. Martinez Roca, Barcelona, 1988.

FREIRE, P. Pedagogia do Oprimido. São Paulo: Paz e Terra, 1987.

. Ação cultural para a liberdade e outros escritos. Rio de Janeiro, Paz e Terra, 1981. $\overline{1978}$.

Educação como prática da liberdade. Rio de Janeiro, Paz e Terra,

GADOTTI, M. Convite à leitura de Paulo Freire. Scipione. São Paulo. 1991.

JOURNAL OF EDUCATION, Boston University, Vol. 169, n. 3, 1987.

KEMMIS, S. \& MACTAGGART R. Como planificar la investigación-acción. Laertes. Barcelona.1988.

SHOR, I. Developing Student Autonomy in the Classroom. Equity and Excellence. Massachusetts. Bergin \& Garvey Publishers, 1987.

SNYDERS, G. A escola pode ensinar as alegrias da música? São Paulo: Cortez Editora, 1992.

WILLEMS, E. El valor humano de la educación musical. Barcelona: Editora Paidós 1994. 
